\title{
Macroeconomic identification of the priced APT factors on the Johannesburg Stock Exchange
}

\author{
Paul van Rensburg \\ Department of Accounting and Finance, University of Natal, Private Bag X1, Dalbridge, 4014 Republic of South Africa
}

Received September 1996

\begin{abstract}
Employing prespecified macroeconomic variables as potential priced factors, the Arbitrage Pricing Theory (APT) may be modelled as a non-linear seemingly unrelated regression with across equation restrictions. This portrayal allows for the simultaneous estimation of factor sensitivities and the risk premium associated with each factor. The following macroeconomic variables were tested as potential factors: unexpected movements in (rand) gold returns, (dollar) returns on the Dow-Jones Industrial Index, the term structure of interest rates and inflation expectations together with the 'residual market factor' of Burmeister \& Wall. Using iterated non-linear seemingly unrelated regression (ITNLSUR) estimation techniques, it was found that all of the above variables except for gold price risk are priced, that is, are associated with statistically significant risk premia.
\end{abstract}

\section{Introduction}

'In SA the APT is arousing academic interest only now. Undoubtedly, the limited number of papers published in the USA indicate that it could suffer from many of the CAPM's problems. But the core task has at least been specified - namely the identification of the significant "priced" factors and the making of these operational. I believe that this core task is a worthwhile challenge to SA investors working in a quite different and severely constrained environment. It would be purely speculative at this point to consider what significant factors might be but I feel that they are unlikely to be the same as those that have been tentatively identified in the USA' (Seneque, 1987: 36).

The pricing of financial assets is one of the most important and popular avenues for research in the discipline of financial economics. During the 1960 s and early 70 s the predominant theoretical paradigm underlying this research was the Capital Asset Pricing Model (CAPM) as developed by Sharpe (1964), Lintner (1965) and Mossin (1966).

However, dissatisfaction with the CAPM has gradually manifested itself over the last two decades. In academic debate, the restrictive assumptions adopted by the theory and the necessity for specifying the 'true' market portfolio have caused dissatisfaction most notably expressed in the work of Roll $(1977 ; 1978)$. In terms of practical application, the specification of a single factor underlying security returns does not do justice to representing the plurality of influences affecting security returns. It also does not aid the investor in taking account of these heterogenous influences when making portfolio management decisions.

The APT attempts to address these shortcomings. It is based on the no-arbitrage condition and requires fewer and less restrictive assumptions than the CAPM. In addition, it is a multifactor model allowing more than one type of risk to affect the returns of financial assets. However, the main obstacle to the practical implementation of the APT is that it does not reveal on an a priori basis what these risk factors are. Indeed, there are good reasons to suggest that the number and nature of these factors is likely to change over time and between economies. The identification of the priced APT factors is essentially an empirical issue. The central concern of this study is to attempt to identify the priced APT factors operational on the JSE over the period January 1980 to December 1989.

\section{Arbitrage pricing theory}

The APT was developed by Ross (1976). Subsequently several theoretical refinements have been made (Ohlson \& Garman, 1980; Shanken, 1982; Huberman, 1982; Chen \& Ingersoll, 1983; Dybvig, 1983; Grinblatt \& Titman, 1983; and Ingersoll, 1984; inter alia).

The APT is based on the assumptions that

1. markets are perfectly competitive and frictionless;

2. investors are risk averse wealth maximizers; and

3 . individuals homogeneously believe that the random returns for the set of $\boldsymbol{n}$ securities under consideration is generated by a k-factor process of the form:

$$
R_{i t}=E\left(R_{i t}\right)+\sum_{k=1}^{K} b_{i k} f_{k t}+\varepsilon_{i t}
$$

where:

$\mathbf{R}_{\mathrm{il}}=$ actual returns earned by asset $i$ in time period $t$, where $i=1,2 \ldots n$ and $t=1,2 \ldots \mathrm{T}$

$\mathrm{E}\left(\mathrm{R}_{\mathrm{it}}\right)=$ the expected rate of return of asset $i$ for period $t$ at the beginning of period $t$

$f_{\mathrm{kt}}=k$ th risk factor that impacts on asset $i$ 's returns, where $k=1,2 \ldots \mathrm{K}$. All risk factors have a mathematical expectation of zero, that is $\mathrm{E}\left(f_{\mathrm{kl}}\right)=0$

$b_{i k}=a$ coefficient that measures the sensitivity of $R_{i 1}$ to movements in the common factor $f_{\mathrm{kt}}$

$\varepsilon_{i i}=$ a stochastic error term specific to asset $i$ in period $t$ which measures unexplained residual return where $\mathrm{E}\left(\varepsilon_{\mathrm{ii}}\right)=0 ; \mathrm{E}\left(\varepsilon_{\mathrm{it}} \varepsilon_{\mathrm{jl}}\right)=0$ for all $i \neq j$ and $\mathrm{E}\left(\varepsilon_{\mathrm{i}} f_{\mathrm{kl}}\right)=0$ (Ross, 1976: 342).

The central intuition of the APT is that all portfolios that satisfy the conditions of (a) using no wealth and (b) having no risk must earn no return on average. If it is assumed that $n$ is sufficiently large and that the noise vector $(\varepsilon)$ is sufficiently diverse to allow the law of large numbers to hold, Ross (1976) mathematically demonstrates that the expected return of the $i$ th asset in period $t$ must be a linear combination of a constant vector and the sensitivity of that asset's returns to the factors: 


$$
E\left(R_{i t}\right)=\lambda_{o t}+\sum_{k=1}^{K} b_{i k} \lambda_{k}
$$

for each asset $i$

An interpretation of equation 2 which strongly suggests itself is that $\lambda_{11}=$ the return on a risk free asset $\left(R_{41}\right)$, if such an asset should exist in reality. If a true risk free asset does not exist $\lambda_{4 n}=$ the return on a hypothetical asset with a zero sensitivity to all factors (i.e. $b_{i 1}=b_{12}=\ldots b_{i k}=0$ ). $\lambda_{k}$ can be seen as representing the risk premium associated with bearing a unitary sensitivity to factor $k$.

Substituting the fundamental APT pricing relation (equation 2) into the linear factor model (equation 1) we obtain what Berry et al. (1988: 31) refer to as the "full APT":

$$
R_{i t}=\lambda_{O t}+\sum_{k=1}^{K} b_{i k} \lambda_{k}+\sum_{k=1}^{K} b_{i k} f_{k t}+\varepsilon_{i}
$$

When compared to equation 1 , it can be seen that restrictions have been placed on the intercept term of the linear factor model (LFM). These restrictions embody and, indeed, are a direct algebraic consequence of, the no-arbitrage conditions. Note that econometric estimation of the LFM would not be the estimation of an APT model because, as mentioned above, the absence of arbitrage profits is not incorporated in the LFM.

\section{Significant prior research}

Early research on the APT, such as Roll \& Ross (1980), utilized the statistical technique of factor analysis. Page (1986) and Barr (1990) conducted factor analytically orientated studies on the JSE.' This approach is fraught with numerous and well documented methodological difficulties (see Shanken, 1982; Dhrymes, Friend \& Gultekin, 1984; and Conway \& Reinganum, 1988; inter alia). Perhaps the most important practical consideration is that the factors extracted are merely statistical constructs that are not necessarily observable or identifiable with any single economic variable.

'At hest, perhaps factor analysis can be used to confirm a prespecified factor structure. Economic theories should provide a better understanding of a meaningful factor structure than does exploratory factor analysis. The current trend of prespecifying the factors seems to be a more promising avenue of research in the search for a stable and meaningful factor structure' (Conway \& Reinganum, 1988: 15).

Chen, Roll \& Ross (1986) present the first published study that adopts the prespecified variable approach in an attempt to explicitly identify the macroeconomic nature of the APT factors. Their study was conducted in the US financial environment over the period January 1953 to November 1982.

Employing a multivariate version of the Fama \& MacBeth (1973) 'two-step' technique, four priced factors were identified. They were unexpected changes in industrial production, risk premia. twists in the yield curve and also measures of unanticipated inflation and changes in expected inflation during periods when these inflation variables were volatile.
Burmeister \& Wall (1986) introduced the residual market factor (to be discussed later) and regressed a number of portfolio and individual share returns on this variable together with similar macroeconomic variables to those identified as priced by Chen et al. Burmeister \& Wall found that most portfolios and assets had significant sensitivity coefficients to the factors. In addition, it was found that the value of these sensitivities display significant variation across securities, pointing to the potential usefulness of the APT.

McElroy \& Burmeister (1988) used iterated non-linear seemingly unrelated regression (ITNLSUR) techniques to estimate factor sensitivities and risk premia jointly on a sample of individual shares. Monthly return data for a sample of 70 randomly selected securities over the period January 1972 to December 1982 were used. The explanatory variables employed in this study are similar to those utilized by Burmeister \& Wall.

McElroy \& Burmeister found that all five factors (innovations in sales, inflation, the term structure of interest rates, default premia and the residual market factor) were priced and that they accounted for $30-50 \%$ of the variation in the returns of individual firms. Comparing the APT with a linear factor model using nested hypothesis tests they found that

'... the across-equation pricing restrictions implied by the APT are consistent with these data, although the evidence is not strong' (1988: 39).

In addition, using a chi-squared test, they concluded that '... Factors other than the S\&P 500 index used as a market proxy are essential for explaining actual asset returns' (1988: 41).

\section{Share sample selection}

The same sample of shares as utilized by Reese (1993) was employed in this study. Monthly share price data was used from January 1980 to December 1989.

Reese (1993: 41-42) chose her sample according to the following criteria:

1. The shares chosen must be listed for the entire period of the study;

2. The shares chosen must be frequently traded;

3. The shares chosen must represent a large proportion of the capitalization of the JSE and yet must not be biased against smaller firms; and

4. Where possible non-operational firms such as "cashshells' should be excluded.

Reese initially chose the 151 components of the JSE Overall Index as constituting a representative sample. However. only those shares which remained as constituents of this index over the entire sample period were included. This narrowed the sample to 80 shares. She dealt with the problem of thin trading by eliminating all those securities which had not traded for $\mathbf{2 0}$ weeks over the ten-year sample period, or on average two weeks in a year. She was left with a sample of 53 shares.

However, narrowing the sample in this manner introduces a bias towards representing certain sectors rather than others. In particular, mining shares tend to be more frequently traded than other groups. Taking this into account she added another 19 well traded and continuously listed shares to her sample ensuring that they represented those sectors that were 
previously underrepresented (most notably in the financial sector where banks were only allowed to become public companies in 1987). This left her with a final sample of 72 securities. Although precautions were taken to avoid thin trading and to obtain a 'representative' sample, there nevertheless exits an unavoidable 'survivorship bias' to the extent that all shares in the sample are continuously listed for the period of the sample. Table 1 presents a broad overview of the final sample.

Returns on each of these securities were measured as follows:

$$
R_{i t}=\frac{P_{i 1}-P_{i(t-1)}}{P_{i(1-1)}}
$$

where: $\mathrm{P}_{\mathrm{u}}=$ the price of asset $i$ in period $t$.

Due to non availability of data, dividends were excluded from the analysis. This was also the case in Page (1986) and Barr (1990). The effects of this omission are considered in Van Rensburg (1996).

\section{Estimation and selection of candidate factors}

Unexpected movements in the following macroeconomic variables were selected as candidate factors: (dollar) returns on the Dow-Jones Index, inflation expectations, the gold price (in rands), the term structure of interest rates and the 'residual market factor' of Burmeister \& Wall (1986).

As discussed in Van Rensburg (1995), these variables were selected on the basis of fulfilling the $a$ priori characteristics required of priced factors, that is, they represent (a) unexpected movements in (b) macroeconomic variables about which (c) accurate and timeous information is available (Berry, Burmeister \& McElroy, 1988: 29; see also Alexander, Sharpe \& Bailey, 1990: 252-253). The above macroeconomic variables can also be expected to affect either the denominator or numerator of the basic share valuation formula.

The macroeconomic variables used as candidate factors in this study do not exhaust all of the variables that meet these $a$ priori criteria. In unreported tests the All Share Index was regressed on the following variables:

Unexpected movements in

1. inflation (percentages changes in the CPI),

2. the growth rate of manufacturing production

3. the growth rate of retail sales

4. the growth rate of the money supply (M3)

5. the rand-dollar exchange rate

6. the growth rate of building plans passed

7. (percentage changes in) the rand gold price

8. dollar returns on the Dow-Jones Industrial Index

Table 1 Sample composition

\begin{tabular}{lc}
\hline Sector & $\begin{array}{c}\text { \% market } \\
\text { capitalization }\end{array}$ \\
\hline Mining & 66.52 \\
Industrial & 37.14 \\
Financial & 54.16 \\
\hline Total & 60.14 \\
\hline
\end{tabular}

\section{9. inflation expectations}

10. the term structure of interest rates

(Unfortunately GDP data was only available quarterly. Data on South African corporate bonds was considered unreliable).

In only the last four cases was a significant (contemporaneous) relationship found. Thus, invoking the a posteriori criterion that the factors should demonstrate a 'pervasive' impact on securities, only these candidate factors were selected to procede to the next level of testing.

Note that each of the selected variables is, or is directly derived from, a measurable market-related 'price'. There are good reasons to conjecture that movements in prices have many of the 'innovational' characteristics required of APT factors. To the extent that these variables, like share prices, represent the embodiment of expectations and that participants in the above markets are concerned with broadly similar information sets, it can be argued that these commonalities will strengthen the relationship between the prespecified macrovariables and share prices.

Changes in the gold price, the Dow-Jones Index and inflation expectations were also found to significantly affect equity returns in prior South African empirical research (Barr, 1990; Bradfield, 1990; Correia \& Wormald, 1988). To the author's knowledge there are no published studies exploring the relationship between share prices and the term structure of interest rates on the JSE. However, both Chen et al. (1986) and Burmeister \& Wall (1988) found this variable to be priced in the US financial environment.

'Apart from spanning the space of returns the most important property required of appropriate factor measures is that they have a zero expectation at the beginning of month $t$. In particular a macroeconomic factor measure cannot be predictable from its own past' (McElroy \& Burmeister, 1988: 31).

In extracting unexpected movements in the prespecified macrovariables these two criteria are focussed on.

Following Burmeister \& Wall (1986), a constant is added to the factor measurement, where necessary, to ensure that its mean value is zero. (This manipulation is justified by the assumption that the average expected monthly change in the underlying macrovariable is equal to its average realized monthly change over the period of the sample. This assumption conforms to the notion of rational expectations, that rational investors will not consistently over- or underestimate returns over a sustained period of time and is equivalent to assuming that the long-term trend in the underlying macrovariable is expected.)

Correllograms of the factor values were inspected and BoxPierce and Ljung-Box Q statistics were utilized to test the null hypothesis that the values of all of their autocorrelation coefficients up to 12 lags were zero. Where autocorrelation was detected, the component of the initial factor estimate which can be predicted due to this autocorrelation, was removed by extracting the residuals of autoregressive time-series models designed to forecast future values of the factor. These residuals were then taken to represent unexpected movements in the macroeconomic variables.

There is no 'unique' or absolutely optimal set of APT factors. Certain economic forces that influence returns may be closely correlated and, hence, not simultaneously be priced 
due to the effects of multicollinearity. In fact, any set of factors that explain securities' returns will 'work'. However, it is desirable to obtain a set that captures as much of the effects of the ecenomic forces at work as possible without the introduction of unsystematic influences. In addition, the inclusion of the residual market factor aids in alleviating fears of specification errors arising due to ommitted variables (McElroy \& Burmeister, 1988: 41).

\section{Regression of 'market' returns on proposed macro-} economic factors

The JSE Actuaries All Share Index was utilized as a market proxy and regressed on the macroeconomic factors derived above:

$R_{m 1}=b_{m(1)}+b_{m U U(i),(1)} U G O L D_{1}+b_{m U I)} U D_{1}+b_{m U I N F} U I N F_{1}+b_{m U T S D} U T S D_{1}+\varepsilon_{m 1}(s)$

where:

$\mathrm{R}_{\mathrm{mw1}} \quad=$ the return realized on the JSE All Share Index

$\mathrm{b}_{\mathrm{m} t)} \quad=$ the constant, which should represent $\mathrm{E}\left(R_{\mathrm{m}}\right)$ over the period of the sample

$\mathrm{UGOLD}_{1}=$ unanticipated percentage changes in the (rand) gold price

UDJ = unanticipated returns on the Dow-Jones Industrial Index

UINF, = unanticipated changes in inflation expectations, where changes in inflation expectations (INF, are proxied by changes in the three month Banker's Acceptance rate $\left(\mathrm{BA}_{1}\right)$ i.e. $\mathrm{INF}_{1}=\mathrm{BA}_{1}-\mathrm{BA}_{1-1}$ (see Correia \& Wormald, 1987 and Fama, 1976)

$\mathrm{UTSD}_{1}=$ unanticipated changes in the term structure of interest rates, where the term structure of interest rates $\left(\mathrm{TS}_{1}\right)$ is represented by the difference in yields between 10 year government bonds (GILT) and three month Treasury Bills (TBILL $)_{1}$ i.e. $\mathrm{TS}_{1}=$ GILT, $_{1}$-TBILL (see Chen et al., 1986). Changes in the term structure $\left(\mathrm{TSD}_{1}\right)$ is the first difference of $T S_{1}$ i.e. $T S D_{1}=T S_{1}-T_{1-1}$

Table 2 displays the results of this regression.

The Breusch-Godfrey La Grange multiplier test could not reject the null hypothesis of no autocorrelation up to 12 lags at the $5 \%$ level of significance. The White test for heteroscedasticity and model specification indicated that the null hypothesis of no heteroscedasticity could not be rejected at the $5 \%$ level.

All four macrovariables are significant at the $95 \%$ level of confidence. Note the relatively large magnitude of the

Table 2 Regression of 'market' on macroeconomic variables: results

\begin{tabular}{lccc}
\hline Coffficient & Estimate & t statistic & $p$ value \\
\hline$b_{\text {mut }}$ & 0.010 & 1.968 & 0.051 \\
$b_{\text {mUtint.1) }}$ & 0.299 & 2.744 & 0.007 \\
$b_{\text {muls }}$ & 0.367 & 3.203 & 0.002 \\
$b_{\text {muint }}$ & -41.117 & -4.051 & 0.000 \\
$b_{\text {muts! }}$ & -27.805 & -2.476 & 0.015 \\
\hline Adjusted $R^{2}: 0.300$ & & \\
F statistic: 12.414 \\
Durbin-Watson: 1.750 \\
\hline
\end{tabular}

sensitivity coefficients associated with UINF and UTSD. This phenomenon is simply a result of scaling. Unlike UDJ and UGOLD, these variables represent first differences of a measure of returns. As a result one would expect sensitivities to unexpected changes in inflation expectations and the term structure of interest rates to be large relative to those of UDJ and UGOLD.

The residuals from this regression were taken to be UM, the residual market factor, as introduced by Burmeister \& Wall (1986). The residual market factor represents that variation in the 'market' that is unexplained by the prespecified macroeconomic variables. This variable serves a useful 'catch all' purpose and plays a valuable role in terms of model specification (Burmeister \& Wall, 1986: 9).

\section{Descriptive statistics}

Table 3 displays the correlation matrix of the explanatory variables to be utilized in the ensuing regressions together with $\mathbf{R}_{\mathrm{m}}$.

The correlation between UM and the other factors is zero because UM has been specifically constructed to exhibit this characteristic. UM is also strongly correlated with $R_{m}$ because it represents a portion of the variation in $R_{m}$.

In general, most of the explanatory variables exhibit the desirable characteristic of being relatively uncorrelated with each other and relatively more correlated with movements in the market. A notable exception is the strong negative correlation between unexpected changes in the term structure of interest rates and unexpected inflation. The reason for this relation is because the measure of inflation expectations is based on short-term interest rates which are also part of the term structure variable. The existence of this correlation is a warning of the possibility of multicollinearity diluting the effect of these variables individually in the presence of each other and the possibility that the sensitivity coefficient associated with UTSD may be more representative of a 'long bond' effect than a term structure effect.

All four factors affect 'market' returns at the $95 \%$ level of confidence, that is, the JSE All Share Index has statistically significant sensitivity coefficients to all of the five factors. This can be interpreted as positive, but far from definite, indication that these factors' influences are undiversifiable and, as a result, associated with a non-zero risk premium. In view of the above, all four macrovariables and the residual market factor were initially tested as potential priced APT factors.

\section{Methodology and model specification}

A similar methodology to that employed by McElroy \& Burmeister (1988) and Reese (1993) is adopted. An ITNLSUR system is estimated which embodies the APT pricing

Table 3 Correlation matrix: macrovariables

\begin{tabular}{lccccc}
\hline & $R_{\mathrm{m}}$ & UGOLD & UDJ & UINF & UTSD \\
\hline UGOLD & 0.35 & - & - & - & - \\
UDJ & 0.30 & 0.02 & - & - & - \\
UINF & -0.37 & -0.32 & -0.07 & - & - \\
UTSD & 0.05 & 0.11 & -0.03 & -0.65 & - \\
UM & 0.83 & 0.00 & 0.00 & 0.00 & 0.00 \\
\hline
\end{tabular}


restrictions. In this model the sensitivity coefficients $\left(b_{i k} s\right)$ for each share in the sample and the risk premia $\left(\lambda_{k} s\right)$ associated with each factor are measured simultaneously. Those factors associated with statistically significant risk premia are identified as being priced. The reasons for adopting this methodology over the Fama-MacBeth (1973) technique utilized by Chen et al. (1986) are discussed in McElroy \& Burmeister ( 1988).

The arbitrage pricing restrictions can be seen as being manifested in two ways. First the intercept of the linear factor model is constrained as follows for each asset $i$ :

$$
E\left(R_{i t}\right)-R_{1 \prime}=b_{i O}=\sum_{k=1}^{K} b_{i k} \lambda_{k}
$$

Second. the values of the risk premia are constant across each equation in the system. In other words, all assets with the same sensitivity protiles will have the same expected returns. In order for this across equation constraint to be applied, the system equation technique of a seemingly unrelated regression is used. Thus, the following system is estimated:

$$
R_{i t}-R_{f t}=\sum_{k=1}^{K} b_{i k} \lambda_{k}+\sum_{k=1}^{K} b_{i k} f_{k t}+\varepsilon_{i t}
$$

for $i=1, \ldots n$ and $t=1, \ldots T$.

where:

$\mathbf{R}_{n}=$ realized returns on asset $i$ in time period $t$

$\mathbf{R}_{\mathbf{n}}=$ the risk free rate of return at time $t$

$\mathrm{b}_{\mathrm{ik}}=$ the sensitivity of asset $i$ to factor $k$

$\lambda_{k}=$ the risk premium associated with factor $k$

$f_{\mathrm{k} 1}=$ the unexpected movement in factor $k$ at time $t$

$\varepsilon_{11}=$ the error term for asset $i$ at time $t$

Excess returns were chosen as being the right -hand side variable in the ITNLSUR model so that the variation in returns that are not due to the risk profile of the assets but rather due to changes in the risk free rate are not represented in the dependent variables. Should total returns instead be utilized as the dependent variable and the value of $\lambda_{11}$ be estimated, the risk free rate would be constrained to be constant over the period of the sample. Following Bradfield et al. (1988), the 12 month fixed deposit rate is utilized as a proxy for the risk free asset.

Equation 7 may be written in matrix notation as:

$$
\rho_{i}=\sum_{k=1}^{K}\left(\lambda_{k} \tau+f_{k}\right) b_{i k}+\varepsilon_{i}
$$

where:

$\rho_{1}=\left(\mathrm{R}_{11}-\mathrm{R}_{11}, \ldots, \mathrm{R}_{\mathrm{iT}} \mathrm{R}_{\mathrm{iT}}\right)^{\prime}$ for $i=1, \ldots n$

$f_{k}=\left(f_{k 1}, \ldots, f_{\mathrm{kT}}\right)^{\prime}$ for $k=1, \ldots K$

$\varepsilon_{1}=\left(\varepsilon_{11}, \ldots, \varepsilon_{\mathrm{T}}\right)^{\prime}$ for $i=1, \ldots n$ and $\mathrm{l}_{\mathrm{T}}$ is a $T$ dimensional column vector of ones.

This system may, in turn, be re-expressed as follows:

$$
\rho_{1}=\mathrm{X}(\lambda) b_{1}+\varepsilon_{1}
$$

where:

$$
\begin{aligned}
& X(\lambda)=\left(\lambda^{\prime} \otimes \mathfrak{l}_{\mathrm{T}}\right)+F \\
& \lambda=\left(\lambda_{1}, \ldots, \lambda_{\mathrm{K}}\right)^{\prime}
\end{aligned}
$$

$\mathrm{F}=\left(f_{1}, \ldots, f_{\mathrm{K}}\right)$

$b_{1}=\left(b_{11}, \ldots, b_{\mathrm{iK}}\right)^{\prime}$ for $i=1, \ldots n$

and $\otimes$ denotes the Kronecker product.

Stacking the $n$ equations yields

$\left\lceil\rho_{1}\right\rceil\lceil\chi(\lambda) 0 \ldots 0\rceil\left\lceil b_{1}\right\rceil\left\lceil\varepsilon_{1}\right\rceil$

$\rho_{2}=0 \chi(\lambda) \ldots 0 \quad b_{2}+\varepsilon_{2}$

$\left.\left\lfloor p_{n}\right\rfloor\lfloor 0 \quad 0 \quad \ldots \quad \ldots \chi(\lambda)\rfloor\left\lfloor b_{n}\right\rfloor \varepsilon_{n}\right\rfloor$

Which can also be expressed as:

$$
\rho=\left[I_{n} \otimes \chi(\lambda)\right] b+\varepsilon
$$

where:

$\rho=\left(\rho_{1}, \ldots, \rho_{\mathrm{n}}\right)^{\prime}$

$b=\left(b_{1}, \ldots b_{\mathrm{n}}\right)^{\prime}$

$\varepsilon=\left(\varepsilon_{1}, \ldots, \varepsilon_{n}\right)^{\prime}$

and $\mathrm{E}(\varepsilon)=0_{\mathrm{nT}}$ and $\mathrm{E}\left(\varepsilon \varepsilon^{\prime}\right)=\left[\Sigma \otimes \mathrm{I}_{\mathrm{T}}\right]$, where $\Sigma$ is the $n \times n$ variance-covariance matrix of the contemporaneous residuals of assets $i=1, \ldots . n$ and $j=1, \ldots n$.

McElroy \& Burmeister (1988: 32) demonstrate that the APT model does fulfil the necessary condition for non-linear seemingly unrelated regression (NLSUR) estimators to exist.

NLSUR estimators may be obtained in three steps:

1. Equation 10 is estimated via share-by-share OLS. This is the same procedure as followed in the first step of the Fama \& MacBeth (1973) 'two-step' procedure.

As a result a vector of estimates $b_{1}=\left(b_{i 1}+b_{i 1} \ldots+b_{i k}\right)$ is obtained for each share $i$. The intercept term $b_{i t}$ is equal to the cross product sum:

$$
\sum_{k=1}^{K} \lambda_{k} b_{i k}
$$

Unlike in the two-step procedure, the output utilized is not $b_{i}$ but the residual vector from these regressions $\varepsilon_{\mathrm{i}}$ where

$$
{ }_{i}=\rho_{i}-\sum_{k=1}^{K} b_{i 0^{l} t}+f_{k} b_{i}
$$

2. The residual vector $\varepsilon$ is used to obtain an estimate of $\Sigma$ :

$$
\Sigma=\left[T^{-1} \varepsilon_{i} \varepsilon_{j}\right]
$$

3. The estimated variance-covariance matrix is plugged in to the following quadratic form, $\mathrm{Q}$ :

$\mathrm{Q}(\lambda, b, \Sigma)=\left[\rho-\left(I_{\mathrm{n}} \otimes \chi(\lambda) \mathrm{b}\right]^{\prime}\left[\Sigma^{-1} \otimes I_{\mathrm{T}}\right]\left[\rho-\left(I_{\mathrm{n}} \otimes \chi(\lambda) b\right]\right.\right.$

Values for $\lambda$ and $b$ are chosen so as to minimize the value of this expression.

Equation 12 can be simplified as follows:

$$
\mathrm{Q}(\lambda, b, \Sigma)=\varepsilon^{\prime}\left[\Sigma-1 \otimes I_{\mathrm{T}}\right] \varepsilon
$$

Thus, it can be seen that a weighted sum of squared errors is being minimized with respect to $\lambda$ and $b$ subject to information regarding the estimate of the variance-covariance matrix $\Sigma$.

The procedure above may be repeated, iteration occurring between the estimates of $\Sigma$ and the parameters $\lambda$ and $b$. Residuals from the most recent estimates of $\lambda$ and $b$ are used to 
update the estimate of $\Sigma$. This in turn updates the quadratic form $\mathrm{Q}$, allowing revised estimates of $\lambda$ and $b$. Iteration occurs until estimates of the covariance matrix, $\Sigma$, stabilize. This estimation technique is called an iterated non-linear seemingly unrelated regression (ITNLSUR). See Greene (1990: 509-540) for a textbook account of seemingly unrelated regression techniques. This section also draws on $\mathrm{McEl}$ roy \& Burmeister (1988) and Reese (1993).

\section{ITNLSUR results}

The following equation was simultaneously estimated for all $\mathrm{n}=72$ shares using the ITNLSUR technique:

$$
\begin{aligned}
\rho_{\mathrm{i1}} & =b_{11} \lambda_{1}+b_{12} \lambda_{2}+b_{13} \lambda_{3}+b_{\mathrm{i} 4} \lambda_{4}+b_{15} \lambda_{5}+b_{11} U G O L D_{1} \\
& +b_{12} U D J_{1}+b_{13} U I N F_{1}+b_{14} U T S D_{1}+b_{15} U M_{1}+\varepsilon_{11}
\end{aligned}
$$

for $i=1, \ldots n$ and $t=1, \ldots \mathrm{T}$.

Table 4 displays the values of the risk premia estimated through this regression.

The estimated risk preınia are expressed in monthly proportionate format. Thus, the above results suggest that, for example, an asset with a unitary sensitivity to returns on the DowJones Index and a zero sensitivity to all other priced factors, will have an expected monthly return of 0.014509 or $1.45 \%$ above the risk free interest rate.

The average adjusted $R^{2}$ for this regression is 0.21 . (This figure represents the arithmetic mean of the adjusted $R^{2} s$ of the individual equations estimated in the model and provides a measure of the overall goodness of fit of the regression.) Note that the aim of the ITNLSUR model is not necessarily to have as high an $R^{2}$ as possible but to identify priced sources of risk. The introduction of unsystematic factors will be able to explain much of the variation in security returns but will not represent priced sources of risk. Studies such as Evans \& Archer (1968), Wagner \& Lau (1971) and Statman (1987) suggest that a relatively small proportion of a security's risk is systematic in nature. (The mean adjusted $R^{2}$ of the single factor 'market model' when conducted on each individual share in the sample is 0.24.)

\section{Interpretation of estimated risk premia}

'Since the Arbitrage Pricing Theory and Capital Asset Pricing Models are not inconsistent, it is natural to consider a world in which (1) returns are generated by a factor model, (2) the remaining assumptions of the APT hold, and (3) the assumptions of the CAPM hold'

Table 4 Estimated risk premia for APT model incorporating UGOLD, UDJ, UINF, UTSD and UM as potential priced factors

\begin{tabular}{lcc}
\hline Risk premium & Estimate & $p>\mathbb{I I}$ \\
\hline$\lambda$ UGOLD & -0.00880940 & 0.1836 \\
$\lambda$ UDJ & 0.014509 & 0.0041 \\
$\lambda$ UINF & 0.00021986 & 0.0383 \\
$\lambda$ UTSD & -0.00038208 & 0.0008 \\
$\lambda$ UM & -0.00794139 & 0.1961 \\
\hline
\end{tabular}

(Sharpe, 1984: 21 see also Alexander et al., 1993: 266).

As will be demonstrated, under the assumption that security returns are generated by a linear factor model, the CAPM is nested in the APT which, in turn, is nested in the linear factor model.

The APT itself does not provide theoretical guidance as to the appropriate signs and magnitudes of the risk premia (or for that matter, the estimated sensitivity coefficients). Consequently, this question is an empirical issue and a concern of financial researchers and not of theoreticians.

However, it is possible to 'borrow' capital market theory to obtain some theoretical insight as to the signs of the risk premia. This is achieved by simultaneously assuming the APT and the CAPM to be valid and considering the implications of this assumption for the signs of the APT risk premia.

If the CAPM holds, even though returns are generated by a multifactor model, the expected returns of an asset will be related both to its CAPM beta (B) as well as to its sensitivity coefficients to the priced APT factors. In other words, the following equations representing (a) the pricing relation of the CAPM (equation 15); (b) the LFM underlying the APT (equation 16); and (c) the APT pricing relation (equation 17) are simultaneously valid:

$$
\begin{gathered}
E\left(R_{i}\right)=R_{f}+B_{i}\left(E\left(R_{m}\right)-R_{j}\right) \\
R_{i} b_{i 0}+\sum_{k=1}^{K} b_{i k} f_{k}+\varepsilon_{f} \\
E\left(R_{i}\right)=R_{f}+\sum_{k=1}^{K} b_{i k} \lambda_{k}
\end{gathered}
$$

From equation 16 it follows that:

$$
\vee\left(R_{i}, R_{m}\right)=\operatorname{Cov}\left(\left[b_{i 0}+\sum_{k=1}^{K} b_{i k} f_{k}+\varepsilon_{i}\right] R_{m}\right)
$$

Which can be re-expressed as:

$$
\operatorname{Cov}\left(R_{i}, R_{m}\right)=\sum_{k=1}^{K} b_{i k} \operatorname{Cov}\left(f_{k}, R_{m}\right)+\operatorname{Cov}\left(\varepsilon_{i}, R_{m}\right)
$$

Recognizing that the last term in equation 19 is approximately zero and dividing through by the variance of the 'market portfolio' $\left(\sigma_{\mathrm{m}}^{2}\right)$, the following expression is obtained:

$$
\frac{\operatorname{Cov}\left(R_{i}, R_{m}\right)}{\sigma_{m}^{2}}=\frac{\sum_{k=1}^{K} b_{i k} \operatorname{Cov}\left(f_{k}, R_{m}\right)}{\sigma_{m}^{2}}
$$

However, from capital market theory it is well known that the CAPM beta of an asset $i$ can be derived from the following equation:

$$
B_{i}=\frac{\operatorname{Cov}\left(R_{i}, R_{m}\right)}{\sigma_{m}^{2}}
$$


This allows us to rewrite equation 20 as:

$$
B_{i}=\sum_{k=1}^{K} B_{k}^{*} b_{i k}
$$

Where $\mathrm{B}^{*}$ can be interpreted as the CAPM beta of factor $k$ (Sharpe, 1984: 23). Alternatively, $B^{*}{ }_{k}$ can be interpreted as representing the beta of a security with a unitary sensitivity to factor $k$ and a zero sensitivity to all other factors.

Equation 22 can be substituted for beta in the CAPM equation:

$$
E\left(R_{i}\right)=R_{f}+\sum_{k=1}^{K} B_{k}^{*} b_{i k}\left(E\left(R_{m}\right)-R_{j}\right)
$$

which can be re-expressed as:

$$
E\left(R_{\mathrm{i}}\right)=R_{1}+\lambda_{\mathrm{II}} B_{1}{ }^{*} b_{\mathrm{il}}+\lambda_{\mathrm{m}} B_{2}{ }^{*} b_{\mathrm{i} 2} \ldots \lambda_{\mathrm{II}} B_{\mathrm{K}}{ }^{*} b_{\mathrm{ix}}
$$

Now given that the APT holds,

$$
E\left(R_{i}\right)=R_{1}+\lambda_{1} b_{i 1}+\lambda_{2} b_{12} \ldots \lambda_{\mathrm{K}} b_{1 \mathrm{~K}}
$$

It follows that, if equations 15 and 17 are simultaneously valid, the following relationship must hold:

$$
\lambda_{k}=\lambda_{m} B_{k}^{*}
$$

for all priced factors $k=1, \ldots, K$.

In other words, the CAPM may be envisaged as a restricted form of the APT, that is, where equation 25 holds for all of the priced factors (Sharpe, 1984).

Noting that $\operatorname{Cov}\left(R_{i}, R_{m}\right)=\operatorname{Corr}\left(R_{i}, R_{m}\right) \sigma_{i} \sigma_{m}$, equations 20 and 25 imply that factor risk premia should have positive values if the movement of that factor is positively correlated with the 'market portfolio' and will have negative values if a negative correlation exists (assuming a positive 'market risk premium', $\lambda_{\mathrm{m}}$ ). This accords with expectations if mean variance maximizing behaviour is assumed on the part of investors.

In Table 3, the correlation of each macroeconomic variable factor with returns on the 'market' can be observed. Thus, according to capital market theory it would be expected that UGOLD, UDJ, UTSD and UM have positive risk premia whereas UINF should have a negative risk premium.

\section{Estimation of the ITNLSUR excluding gold price risk}

The results of the above ITNLSUR suggest that over the period 1980 to 1989 , gold price risk was not rewarded with a significant risk premium. It is, perhaps, surprising to note that gold price risk is not priced given the importance of this variable to the South African economy. Mining shares are not underrepresented in the share sample and, in fact, their proportion of market capitalization is higher than that of the industrial component of the sample (see Table 1). However, examining the magnitudes of the sensitivity coefficients estimated in Van Rensburg (1995), it can be seen that, although the mining and mining financial sectors displayed significant positive sensitivities to unexpected movements in the gold price, the industrial and financial share portfolios were not affected by this variable, suggesting the possibility that it is more industry than market related in the breadth of its influence.

The correlation matrix presented in Table 3 does not indicate that gold is excessively highly correlated with any of the other factors and a blatant situation of multicollinearity does not appear to have been the case in the estimation of (14). To confirm that it was not the influence of the other factors which diluted the ceteris paribus influence of gold price risk to the extent that it appeared insignificant, the ITNLSUR model was reconducted omitting all other factors besides gold price risk. As can be seen in Table 5 this variable is still not priced.

Bearing the above considerations in mind, the ITNLSUR model was re-estimated but UGOLD was omitted and the residual market factor was respecified (U). ${ }^{2}$ Thus, the following system was estimated:

$$
\begin{aligned}
\rho_{11} & =b_{11} \lambda_{1}+b_{12} \lambda_{2}+b_{13} \lambda_{1}+b_{14} \lambda_{4}+b_{11} U D J_{1} \\
& +b_{12} U I N F_{1}+b_{13} U T S D_{1}+b_{14} U_{1} \varepsilon_{11}
\end{aligned}
$$

for $\mathrm{i}=1, \ldots n$ and $t=1, \ldots \mathrm{T}$.

The estimated risk premia from this regression are reported in Table 6.

The average adjusted $R^{2}$ of the model was 0.20 .

As can be seen, all of the prespecified macroeconomic variables are priced at the $99 \%$ level of confidence. The respecified residual market factor, $\mathrm{U}$, is priced at the $95 \%$ level of confidence. All of the macrovariables have risk premia possessing signs that accord with prior expectations. For example, the risk premium associated with sensitivity to inflation expectations is negative as is the correlation between movements in this factor and the market. (This can be interpreted as indicating that investors perceive it as desirable to hold securities that tend to have higher returns as inflationary expectations are revised upwards (and share returns tend to move downwards) and are willing to 'pay' a premium for these assets).

However, $\mathrm{U}$ has a positive correlation with the market but has a negative risk premium which is significant at the $5 \%$ level. Had this variable been strongly insignificant this would have implied that the prespecified macrovariables on their own capture all but an insignificant amount of the systematic

Table 5 Estimated risk premia for APT model incorporating only UGOLD as a potentially priced factor

\begin{tabular}{lcc}
\hline Risk premium & Estimate & $p>|t|$ \\
\hline$\lambda$ UGOLD & 0.00259912 & 0.4128 \\
\hline
\end{tabular}

Table 6 Estimated risk premia for APT model incorporating UDJ, UINF, UTSD and $U$ as potentially priced factors

\begin{tabular}{lcc}
\hline Risk premium & Estimate & $p>|t|$ \\
\hline$\lambda$ UDJ & 0.027869 & 0.0001 \\
$\lambda$ UINF & -0.00025640 & 0.0002 \\
$\lambda$ UTSD & 0.00027866 & 0.0001 \\
$\lambda U$ & -0.00787043 & 0.0489 \\
\hline
\end{tabular}


risk affecting the securities' returns. Nevertheless, its lower confidence level together with its theoretically inconsistent sign may, perhaps, be an indication of the fact that the variable does not belong in the model (Gujarati, 1988).

(Employing principal factor analysis to decompose $\mathrm{U}$, it was found that the reason for the negative premium associated with the residual market factor is the influence of a priced 'industrial' factor with a negative risk premium which, under the above model specification, is embodied in U [Van Rensburg, 1996].)

\section{Conclusion}

The aim of this study is to identify the 'priced' macroeconomic variables underlying percentage price movements realized by a representative sample of 72 non-thinly traded securities on the JSE over the period $01 / 01 / 1980$ to $31 / 12$ / 1989.

Employing the ITNLSUR methodology of McElroy \& Burmeister (1988) it was found that unanticipated movements in the Dow-Jones Industrial Index, the term structure of interest rates and inflation expectations (as proxied by innovations in short-term interest rates) are associated with statistically significant and theoretically consistent risk premia over the period of the sample. In addition, the residual market factor, representing that variation in the JSE All Share Index not explained by the above macrovariables, was priced and was associated with a negative risk premium.

Suggestions for further research include rigorous specification and diagnostic testing of the APT model estimated in this study.

\section{Notes}

1. The insights gleaned from previous attempts to identify the priced APT factors on the JSE are acknowledged.

Despite adopting essentially a factor analyctic approach, Barr (1990) claims to ascertain the macroeconomic identity of the 'pricing factors on the JSE'. Employing the covariance-biplot methodology, Barr observed which of a list of twelve prespecified macrovariables accorded most closely with the first two (factor analytic) factors.

However, despite its ingenuity, the methodology adopted by Barr is characterized by the following weaknesses:

(a) Notwithstanding its graphical convenience for the covariance-biplot, the assumption (no statistical testing was conducted) of two factors is not adequately justified. Citing Conway \& Reingaum (1988) as evidence is misleading as their analysis was not conducted in the South African environment. Page (1986) did find two priced factors but the composition of Page's sample differs from that of Barr's in an economically meaningful way. Barr excluded all gold mining indices from his sample of 26 share indices. In contrast. Page explicitly observes one of his (varimax rotated) factors being 'composed exclusively of mining related shares' (1986: 42). Excluding the gold indices from the sample 'because initial research indicated that there was only one macroeconomic factor that dominated the pricing of gold securities in an obvious way, namely the gold price, and this effect tended to dominate the analysis' (1990: 20) allows for more aesthetic results at the cost of misrepresenting reality. (Also note that despite its 'obviousness', gold price risk was, in fact, found not to be priced in this study. Criticism (i) of Reese below is also of relevance here.)

(b) No attempt was made to extract unexpected movements in the candidate macrovariables.

(c) It is not examined whether exposure to any of the prespecified macroeconomic variables are associated with a significantly non-zero risk premium. This is the defining characteristic of a priced factor and without empirically examining this issue no claim can be made to identify priced sources of macroeconomic risk.

Criticisms (a) and (c) together suffice to undermine the drawing of inferences from Barr (1990) regarding the macroeconomic identity of the priced APT factors on the JSE.

Reese (1993) procedes on methodologically firmer ground by adopting the prespecified variable (rather than factor analyctic) approach and uses the systems equation technique of McElroy \& Burmeister to explicitly test whether the candidate macrovariables are able to explain the cross section of share returns. However, her study exhibits the following weaknesses: (i) Reese conducts separate tests on the mining and industrial sectors of the JSE taking account of the fact that different factors drive security prices in these sectors. However, even though mining shares' returns are likely to exhibit sensitivities to different factors than industrial shares, this does not imply that different factors will be priced in each of these two markets. By the diversification argument, attempts to find priced factors specific to particular industries are fundamentally misguided. (ii) Reese identified the expected values of these variables by taking a moving average of the previous twelve month's values. These moving averages were subtracted from actual values of the macroeconomic variables in each period to obtain a measure of unexpected movements in the macrovariables. Attempts to extract unexpected movements are unavoidable 'crude', however, Reese took no measures to ensure that her candidate factors has a mean of zero and were void of autocorrelation as equation (1) assumes. In fact, such is the nature of a moving average that it will systematically underestimate a variable if that variable is engaged in an upward trend and vice versa. (iii) Unfortunately, Reese provided no synthesis of her findings pointing to some indication of a reasonable specification of the APT model. Rather an array of varying combinations of factors that appeared to be priced in either the industrial or mining sectors was tabulated. In all cases, when the residual market factor was excluded from the analysis, the explanatory power of her models were prohibitively weak.

2. The residual market factor, $U$, is derived from the following OLS regression:

$\mathrm{R}_{\mathrm{n} 11}=b_{\mathrm{nn})}+b_{\mathrm{m} 1} U D J_{1}+b_{\mathrm{m} 2} U I N F_{1}+b_{\mathrm{m},} U T S D_{1}+\varepsilon_{\mathrm{m} 1}$ where: $U_{1}=\varepsilon_{\mathrm{mt}}$

\section{Acknowledgements}

The assistance of Patsy Clarke of Computer Services is appreciated. Thanks to Sue Trollip for letting me use her printer. Professor Julian Hofmeyr and Doctor Mike Murray provided valuable feedback on earlier drafts of this article. 
The useful comments of four anonomous referees are also appreciated. All of the mistakes are mine.

\section{References}

Alexander. G.J. Sharpe, W.F. \& Bailey, J.V. 1993. Fundamentals of investments. Englewood Cliffs. New Jersey: Prentice Hall.

Barr, G.D.I. 1990. 'Macroeconomic identification of the pricing factors on the Johannesburg Stock Exchange', South African Journal of Business Management, 21(1): 17-26.

Berry, M.A., Burmeister, E. \& McElroy, M.B. 1988. 'Sorting out risks using known APT factors', Financial Analysts Journal, 44(2): 29-42.

Bradfield, D.J. 1989. 'A note on the estimation problems caused by thin-trading on the Johannesburg Stock Exchange', De Ratione, Summer: 22-25.

Bradfield. D.J. 1990. 'The influence of the NYSE on the risk of JSE stocks'. De Ratione, Winter: 26

Bradfield. D.J.. Barr, G.D.I. \& Aftleck-Graves, J.F. 1988. 'Asset pricing in smallmarkets - the South African case', South African Journal of Business Management, 19(1): 11-21.

Burmeister. E. \& Wall, K.D. 1986. 'The arbitrage pricing theory and macroeconomic factor measures', The Financial Review, 21(1): $1-20$

Burmeister. E. \& McElroy, M.B. 1988. 'Joint estimation of factor sensitivities and risk premia for the arbitrage pricing theory', Journal of Finance, 43(3): 721-735

Burmeister, E.. Wall, K.D. \& Burmeister, J.D. 1986. 'Estimation of unobserved expected monthly inflation using Kalman filtering', Journal of Business and Statistics, 4(2).

Chen. N. \& Ingersoll, J.E. 198.3. 'Exact pricing in linear factor models with finitely many assets: a note', Journal of Finance, 38(3): 985-988.

Chen. N. Roll. R. \& Ross, S.A. 1986. 'Economic forces and the stock market', Journal of Business, 59(3): 383-403.

Conway, D. \& Reinganum, M.R. 1988. 'Stable factors in security returns: identification using crossvalidation', Journal of Business and Economic Statistics, 6: 1-15.

Correia. C. de J. \& Wormald, M.P. 1988. 'The association between stock market returns and rates of inflation', De Ratione, 2(1): 11 18.

Dhrymes, P.J., Friend, I \& Gultekin, B.N. 1984. 'A critical examination of the empirical evidence on the arbitrage pricing theory', Journal of Finance, 39(2): 323-346.

Dybvig. P.H. 1983. An explicit bound on deviations from APT pricing in a tinite economy'. Journal of Financial Economics, 11(4): 483-496.

Evans, J.L. \& Archer, S.H. 1968. 'Diversification and the reduction of dispersion'. Journal of Finance, 23(5): 761-769.

Fama, E.F. \& MacBeth, J.D. 1973. 'Risk, return and equilibrium: empirical tests', Journal of Political Economy, 81: 607-636.

Fama, E.F. 1976. Foundations of finance. Blackwell.

Fama, E. \& Schwert. G.W. 1977. 'Asset returns and inflation', Jour nal of Financial Economics, 5(2): 115-146.

Francis. J.C. 1986. Investments: analysis and management. (fourth ed.). Oxford: McGraw-Hill

Gilbertson. B. \& Goldberg. M. 1981. 'The market model and the Johannesburg Stock Exchange'. Investment Analysts Journal 17 $40-42$.

Greene. W.H. 1990. Econometric analysis. New York: MacMillan.
Grinblatt, M. \& Titman. S. 1983. 'Factor pricing in a finite economy', Journal of Financial Economics, 12(4): 497-507.

Gujarati, D.N. 1988. Basic econometrics. (second edition). Singapore: McGraw-Hill.

Huberman. G. 1982. 'A simple approach to arbitrage pricing theory', Journal of Economic Theory, 28: 183-191.

Ingersoll. J.E. 1984. 'Some results in the theory of arbitrage pricing'. Journal of Finance, 39(4): 1021-1039.

Lintner. J. 1965. 'The valuation of risky assets and the selection of risky investmentsin stock portfolios and capital budgets', Review of Economics and Statistics, 47: 13-47.

McElroy, M.B. \& Burmeister. E. 1988. 'Arbitrage pricing theory as a restricted non-linear multivariate regression model', Journal of Business and Economic Statistics, 6(1): 29-42.

Mossin, J. 1966. 'Equilibrium in a capital asset market', Economet. rica, 34: 768-783.

Ohlson, J.A. \& Garman, M.B. 1980. 'A dynamic equilibrium for the Ross arbitrage model', Journal of Finance. 35(3): 675-684.

Page, M.J. 1986. 'Empirical testing of the arbitrage pricing theory using data from the Johannesburg Stock Exchange, South African Journal of Business Management, 17(1): 29-42.

Reese, B.K. 1993. An empirical study of the APT in South Africa. Unpublished Masters Thesis. Durban: University of Natal.

Roll, R. 1977. 'A critique of the asset pricing theory's tests', Journal of Financial Economics, 4(1): 129-176.

Roll, R. 1978. 'Ambiguity when performance is measured by the securities marketline', Journal of Finance, 33(4): 1051-1070.

Roll, R. \& Ross, S.A. 1980. 'An empirical investigation of the arbitrage pricing theory', Journal of Finance, 35(5): 121-130.

Ross. S.A. 1976. 'The arbitrage theory of capital asset pricing', Journal of EconomicTheory, 13: 341-360.

Ross. S.A. 1977. 'Return, risk and arbitrage'. In I Friend, I \& Bickscher, J. (ed.), Risk and return in finance. Cambridge, Mass.: Balleringer

Ross, S.A., Westerfield, R.W. \& Jaffe, J.F. 1993. Corporate finance. Irwin.

Seneque. P.J.C. 1987. 'Recent developments in the pricing of financial assets', De Ratione, Summer: 28-37.

Shanken, J. 1982. 'The arbitrage pricing theory: is it testable?', Journal of Finance, 37(5): 1129-1140.

Sharpe, W.F. 1964. 'Capital asset prices: a theory of market equilibrium under conditions of risk', Journal of Finance, 19(3): 425442.

Sharpe, W.F. 1984. 'Factor models, CAPMs and the ABT (sic)', Journal of Portfolio Management, 11(1): 21-25.

Statman, M. 1987. 'How many stocks make up a diversified portfolio', Journal of Financial and Quantative Analysis, 22(3): 353364.

Van Rensburg, P. 1995. 'Macroeconomic variables and the Johannesburg Stock Exchange: a multifactor approach', De Ratione. 9(2): 45-63.

Van Rensburg, P. 1996. 'Unification of the factor analytic and prespecified variable approaches to APT factor identification on the JSE', De Rationale, 10(2) (forthcoming).

Wagner, W.H. \& Lau, S. 1971. 'The effect of diversification on risk', Financial Analysts Journal, 27(5): 48-53 